\title{
Polymer-Supported Carboxylate as a New Polymeric Reagent for Synthesis of Alkyl Esters
}

\author{
Mohammad Ali Karimi Zarchi, BiBi Fatemeh Mirjalili, and Nahid Ebrahimi \\ Department of Chemistry, College of Science, Yazd University, Yazd, Iran. "E-mail: makarimitavazduniace ir \\ Received December 6, 2007
}

Key Words : Polymeric reagent, Alkyl ester, Polymer supported carboxylate, Crosslinked poly(4-vinylpyridine)

Polymer supported reagents especially anion exchange resins have been widely applied in organic synthesis. ${ }^{i-k}$ These polymeric reagents are generally used in single step reactions. Their main advantage over monomeric reagents is their insolubility in the reaction medium and consequently the easier workup by a simple filtration. The reactions can often be driven to completion by using excess of these reagents without the fear of separating the unspent reagent from the desired products. The spent polymeric reagents can usually be removed quantitatively and regenerated. In addition, anions bound to the macroporous resin have the advantage that they often react sucessfully in non-polar solvents.

The ester group is an important functional group that can be synthesized in a number of different ways such as acylation of alcohols," oxidation of aldehydes, ${ }^{10}$ addition of carboxylic acids to alkenes," reaction of carboxylic acids with diazomethane, ${ }^{12}$ Bayer-Villiger oxidation of ketones, ${ }^{13}$ reaction of organoboranes wilh $\alpha$-halo esters, ${ }^{14}$ rearrangement of $\alpha$-haloketones (Favorskii reaction) ${ }^{15}$ and especially for large scale operation by reaction of carboxylate salts ${ }^{16}$ or Amberlite IR $\Lambda-904$ supported carboxylate ion ${ }^{17}$ with alkyl halides or tosylates. Sodium carboxylate, however, has been the reagent most widely used. Unfortunately, each of these methods sulfer from at least one of the following disadvantages: (1) the yields of the reactions are low, (2) the reaction has to be carried out in the presence of phase transfer calalyst, (3) the reaction mixture has to be acidified or the reaction has to be calalyzed by a base such as pyridine, and (4) tedious work-up procedure.

Polymer-supported carboxylate ion overcomes most of the above mentioned disadvantages. In this study we wish to report an important, eflicient, and casy method for preparation of alkyl acelate or alkyl formate esters from crosslinked poly(4-vinylpyridinium) acelate (I) or crosslinked poly(4-vinylpyridinium) formate (II) with alkyl halides (Scheme 1).

While there are numcrous applications ol solid-supported reagents and scavengers only a lew examples for the Formation of esters were described. Solid-supported acids were used as catalysts in the esterification of carboxylic acids with alcohols. ${ }^{18}$ Carboxylates, generated with solidsupported organic bases, were alkylated with alkyl halides. ${ }^{7}$

Solid-supported organic bases were also used as scavenger resins in the esterification of benzyl alcohol with benzyl chlorides, giving elean benzyl esters in high yields. ${ }^{\text {th }} \Lambda$ modification of the Mitsunobu reaction with resin-bound triphenylphosphine and soluble di-t-butylazodicarboxylate was described, that allowed for the isolation of pure products without chromatography. ${ }^{20} \Lambda$ very recent report described the alkylation of carboxylic acids with carbenium ions, generated from polymer-supported triazines, for the ester formation."

We report here a convenient and general procedure for the synthesis of esters from alkyl halides and polymer-supported carboxylate ion that readily prepared from employing the commercially available poly(4-vinylpyridine) ( $2 \%$ crosslinked with DVB) resin as the solid-supported condensation reagent. Crosslinked poly( $N$-methyl-4-vinylpyridinium) acetate (I) and crosslinked poly( $\mathrm{N}$-methyl-4-vinylpyridinium) formate (II) were prepared by an exchange reaction between crosslinked poly( $N$-methyl-4-vinylpyridinium) iodide with a slight exeess of sodium acetate or sodium formate solution in water. Using these heterogencous reagents converted benzyl halides to benzyl acetate or benzyl formate esters in acelone under rellux condition.

The advantages of this method are: 1) the reaction can be perforned in non-aqueous medium; 2) an exeess of the reagent can be used; 3) the product can be obtained by simple filtration and evaporation of the solvent; and 4) the polymeric reagent is easily regenerable with a sodium acetatc or sodium formate solution.

Crosslinked polymers (I) and (II) can be casily prepared and used as mild and elficient polymeric reagents for conversion of benzyl halides to the corresponding benzyl acelate and benzyl formates. It was proved that acetone is the best solvent for these reactions. In these conversions, the best molar ratio of reagend/substrate proved was 1.5 , but

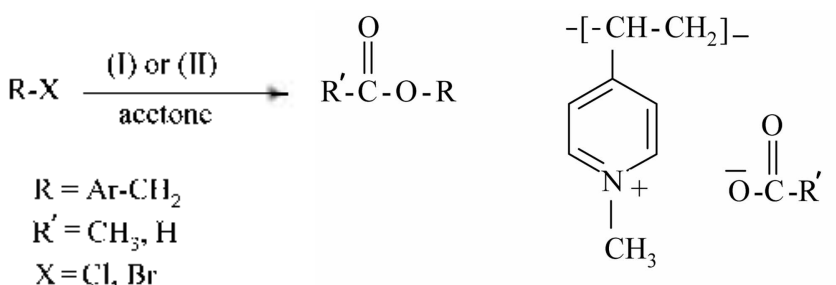

(I): $\mathrm{R}^{\prime}=\mathrm{CH}_{3} \quad$ (II): $\mathrm{R}^{\prime}=\mathrm{H}$ 
Table 1. Conversion of benzyl halides to their corresponding benzyl acetale or benzyl formates with polymer (1) or polymer (II) in acelone under reflux condition

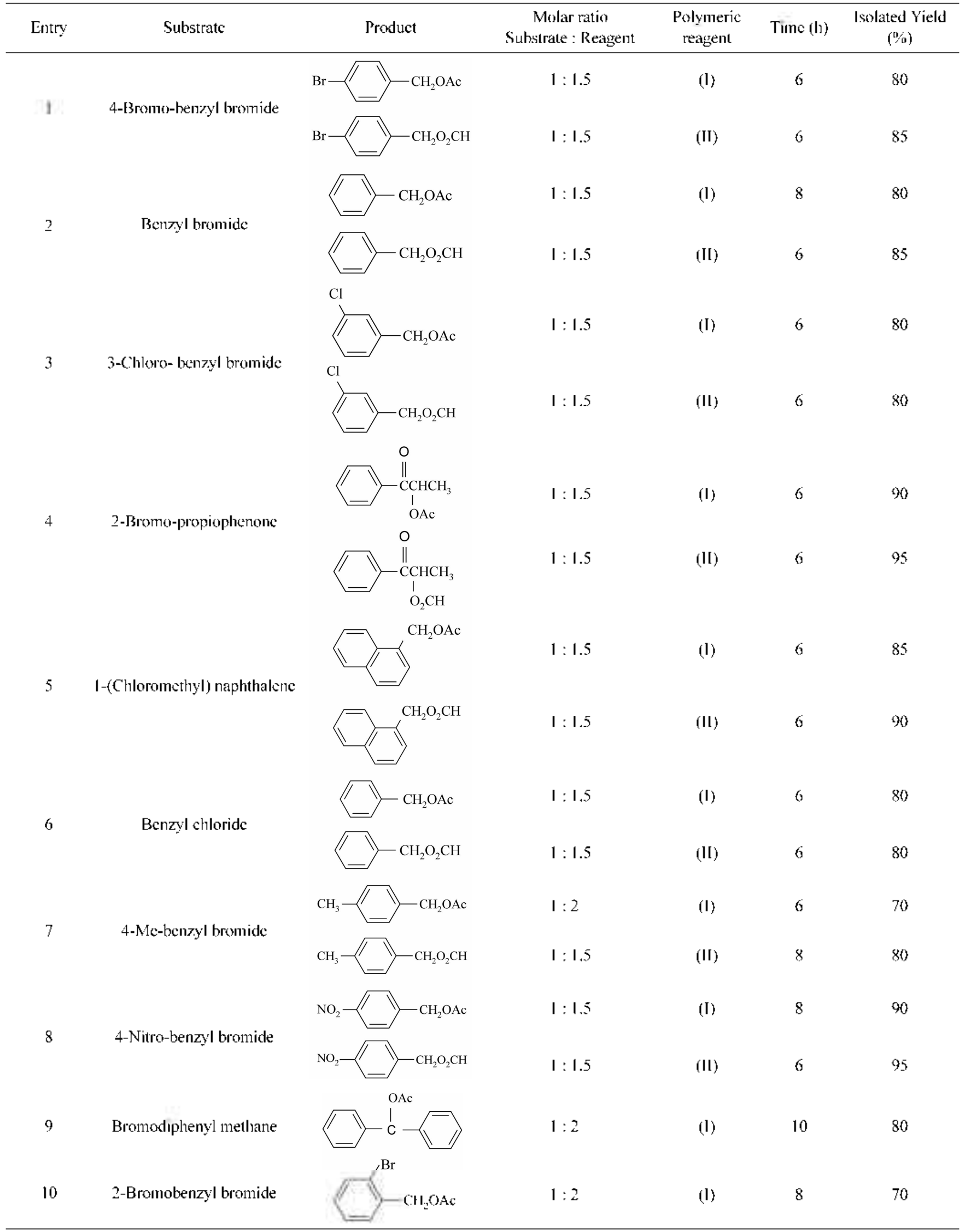


for secondary benzyl halides, 2-substituted benzyl halides and benzyl halides with electron donor group on their rings, was 2 . The capacities of these polymers were detemined by potentiometric titration of filtrates with a $0.1 \mathrm{~N}$ solution of silver nitrate. The capacity of polymer (I) was $0.86 \mathrm{mmol} / \mathrm{g}$ of the polymer, and the capacity of polymer (II) was 0.91 $\mathrm{mmol} / \mathrm{g}$ of the polymer. As expected, capacity of polymer (II) is greater than polymer (I), because acetate ion is more steric than the formate ion and hence the polymer (II) reacts faster than polymer (I) with benzyl halides (Table 1 ).

The products were identified by their FT- IR and ${ }^{1} \mathrm{H}-\mathrm{NM} R$ spectral data and by comparison of their TLC with those of authentic samples. As expected, benzyl bromides were reacted as alkylating agents better than benzyl chlorides. It was found that an electron acceptor group on the ring of benzyl halides increased the positive charge on the bonded carbon to the leaving group and the yield of the reaction increased (Table 1).

\section{Experimental Section}

General. Chemicals were purchased from Fluka, Merck and Aldrich chemical companies. Yields refer to isolated products. Crosslinked poly (4-vinyl pyridinium) carboxylate ion was synthesized according to our procedure. The carboxylic ester products were characterized by comparison of their FT-IR and ${ }^{1} \mathrm{H}-\mathrm{NMR}$ spectral data and by comparison of their TLC chromatogram with those of authentic samples. The FT-IR and 'H-NMR spectra were recorded on a MagnaFT-IR, T. M, Nicollet (model 550) and Perkin-Elmer Hitachi $(60 \mathrm{MHz})$ spectrophotometer respectively.

Preparation of quaternized crosslinked poly(4-vinylpyridinium) iodide. Crosslinked poly(4-vinylpyridine) (1.0 g) was added to an excess methyl iodide in a round-bottomed flask $(50 \mathrm{~mL})$ and stirred for $24 \mathrm{hrs}$ at room temperature. The mixture was filtered and washed with acetone. It was then dried under vacuum at $40^{\circ} \mathrm{C}$. The weight of the dried poly(4-vinylpyridinium) iodide was $2.3 \mathrm{~g}$.

Preparation of quaternized crosslinked poly(4-vinylpyridinium) acetate (I). Crosslinked poly(4-vinylpyridinium) iodide ( $2.3 \mathrm{~g})$ was added to an excess aqueous acetate solution in a round-bottomed flask $(100 \mathrm{~mL})$ and stirred for $24 \mathrm{~h}$ at room temperature. The mixture was filtered and washed with distilled water $(5 \times 10 \mathrm{~mL})$. It was then dried under vacuum at $40^{\circ} \mathrm{C}$. The weight of the dried poly (4vinylpyridinium) acetate was $1.67 \mathrm{~g}$. The capacity of the polymer was determined by potentiometric titration of filtrates with $0.1 \mathrm{~N}$ solution of silver nitrate and it was equal to $0.86 \mathrm{mmol}$ of acetate ion per gram of polymer.

Preparation of quaternized crosslinked poly(4-vinylpyridinium) formate (II). Crosslinked poly(4-vinylpyridinium) iodide $(2.3 \mathrm{~g})$ was added to an excess aqueous solution of sodium formate in a round-bottomed flask ( 100 $\mathrm{mL}$ ) and stirred for $24 \mathrm{~h}$ at room temperature. The mixture was filtered and washed with distilled water $(5 \times 10 \mathrm{~mL})$. It was then dried under vacuum at $40^{\circ} \mathrm{C}$. The weight of the dried poly(4-vinylpyridinium) formate was $1.54 \mathrm{~g}$. The capacity of the polymer was determined by potentiometric titration of filtrates with a $0.1 \mathrm{~N}$ solution of silver nitrate and it was equal to $0.91 \mathrm{mmol}$ of acetate ion per gram of polymer.

General procedure for reaction of benzyl halides with crosslinked poly(4-vinylpyridinium) acetate (I) or formate (II). To a mixture of benzyl halide $(1 \mathrm{mmol})$ and acetone $(10 \mathrm{~mL})$ in a round-bottomed flask $(100 \mathrm{~mL}), 1.5-$ $2.0 \mathrm{mmol}$ of polymer (I) or polymer (II) was added, and the mixture was stirred at reflux for $6-10 \mathrm{~h}$. Reaction monitoring was accomplished by TLC with chloroform $/ n$-hexane ( 70 to 30 ) as eluent. The products were obtained in $30-95 \%$ yields. The spent polymeric reagent was regenerated by treatment with sodium acetate or sodium formate solution.

Preparation of 4-bromobenzyl acetate with polymer (I), a typical procedure. To a suspension of crosslinked poly(4-vinylpyridinium) acetate (I) $(1.72 \mathrm{mmol}, 2.0 \mathrm{~g})$ in acetone $(10 \mathrm{~mL})$ was added 4-bromobenzyl bromide $(1.15$ mmol, $0.29 \mathrm{~g}$ ). The mixture was stirred for $6 \mathrm{~h}$ at reflux condition. Reaction monitoring was accomplished by TLC with chloroform $/ n$-hexane ( 70 to 30 ) as eluent. The product was obtained in $80 \%$ yield $(0.21 \mathrm{~g})$ by preparative TLC., FTIR: $v_{\max }$ (neat) $1736(\mathrm{C}=\mathrm{O}$, ester $), 1490(\mathrm{C}=\mathrm{C}), 1012,1226$ $(\mathrm{C}-\mathrm{O}), 1377\left(\mathrm{CH}_{2}\right.$ and $\left.\mathrm{CH}_{3}\right) 800$ (p-subst) $\mathrm{cm}^{-1} \cdot{ }^{1} \mathrm{H}$ NMR $\left(60 \mathrm{MHz}_{2} \mathrm{CDCl}_{3}\right): \delta 2.0\left(3 \mathrm{H}, \mathrm{s}, \mathrm{CH}_{3}\right) 5.0\left(2 \mathrm{H}, \mathrm{s}, \mathrm{CH}_{2}\right) 7.0$ $7.4(4 \mathrm{H}$, arom)

Preparation of 4-bromobenzyl formate with polymer (II), a typical procedure. To a suspension of crosslinked poly (4-vinylpyridinium) fonnate (II) (1.81 mmol, $2.0 \mathrm{~g}$ ) in acetone $(10 \mathrm{~mL})$ was added 4-bromobenzyl bromide $(1.2$ mmol, $0.3 \mathrm{~g}$ ). The mixture was stirred for $6 \mathrm{~h}$ at reflux condition. Reaction monitoring was accomplished by TLC with chloroform $/ n$-hexane ( 70 to 30 ) as eluent. The product was obtained in $85 \%$ yield $(0.20 \mathrm{~g})$ by preparative TLC., FTIR: $v_{\max }$ (neat) $1724(\mathrm{C}=\mathrm{O}$, ester), $1489,1595(\mathrm{C}=\mathrm{C}), 1011$, $1155(\mathrm{C}-\mathrm{O}), 1430\left(\mathrm{CH}_{2}\right) 808$ (p-subst) $\mathrm{cm}^{-1} .{ }^{1} \mathrm{H}$ NMR $(60$ $\left.\mathrm{MHz}_{3} \mathrm{CDCl}_{3}\right): \delta 5.0\left(2 \mathrm{H}, \mathrm{s}, \mathrm{CH}_{2}\right) 7.0-7.4(4 \mathrm{H}$, arom $), 8.2$ $(1 \mathrm{H}, \mathrm{s})$.

\section{References}

I. Sherringlon, D. C.; Hodge, P. Synthesis and Separations Using Futhotiontal Pohtners; John Wiley and Sons: 1988.

2. Sherrington, D. C.; Hodge, P. Polymer Stpported Reactions in Organic Synthesis; John Wiley and Sons: 1980.

3. Takemolo, K.; Inaki, Y.; Otenbrile, R. M. In Functional Monomers and Polymers; Marcel Dekker Inc.: New York, 1987.

4. (a) Akelah, A.; Sherrington, D. C. Chem. Rev, 1981, 81, 577, (b) Akelah, A.; Sherrington, D. C. Polym. 1984, 24, 1369.

5. Steven, V. L.; Ion, R. B.; Robert, N. B.; Philip, S. J.; Andrew, G. L.; Deborah, A. L.; Marcella, N.; James, S. S.; Storer, R. I.; Stephen, J. T. J. Chem. Soc. Perkin Trons. 1 2000, 3815.

6. Tamami, B.; Iranpoor, N.; Karimi Zarchi, M. A. Polymer 1993, 34,2011 .

7. Tamami, B.; Karimi Zarchi, M. A. Eur. Polynt. J. 1995, 13, 715.

8. Karimi Zarchi, M. A.; Zarei, A. J. Chin. Chen. Soc. 2005, 52, 309.

9. (a) Fersht, A. R.; Jencks, W. P. J. Am. Chem. Soc. 1970, 92, 5432. (b) Holle, G.; Steglich, W.; Vorbruggen, H. Angew. Chem. Intern. Ed. Engl. 1978, 17, 569. (c) Jampel, E. G; Lecorte, G; Wakselman, M. Tetrahedron Lett. 1970, 11, 1157. (d) Mukaiyama, 
T.; Usui, M.; Shimada, E.; Saigo, K. Chem. Lett. 1975, 1045. (e) Corey, E. J.; Nicolaou, K. C.J. Am. Chem. Soc. 1974, 96, 56I4. (f) Nicolaou, K. C. Tetrahedron 1977,33,683.

10. Corey, E. J.; Gilman, N. W.; Ganem, B. E. J. Am. Chem. Soc. $1968,90,5616$.

II. (a) Mcrin, R. D.; Bearse, A. E. Ind. Eng. Chem. 1951, 43, 1596. (b) Dalgleish, D. T.; Nonhebel, D. C.; Pauson, P. L. J. Chem. Soc. Perkin Ttrans. 1 1971, 1174. (c) Peterson, P. E.; Bopp, R. I.; Cherli, D. M.; Curran, E. L.; Dillard, D. E.; Kamat, R. J. J. An. Chem. Soc. 1967, 89, 5902 .

12. (a) White, E. H.; Maskill, H.; Woodcock, D. J.; Schroeder, M. A. Tetrahedron Lett, 1969, 10, 1713 . (b) White, E. H.; Scherrer, H. Tetrahedron Lett. 1961, 2, 758 .

13. (a) Hassall, C. H. Org. React. 1957, 9, 73. (b) House, H. O. In Modern Synthetic Reactions, 2nd ed.; BenJamin. W. A.: Menlopark Colifornia, 1972; p 325.

14. Brown, H. C.; Rogic, M. M. J. Am. Chem. Soc. 1969, 9J, 2146.

15. (a) Brown, H. C.; Rogic, M. M. J. Am. Chem. Soc. 1969, 91, 2146. (b) Kende, A. S. Org. React. 1960, M, 261.
16. (a) Akhrem, A. A.; Ustynyuk, T. K.; Titov, Y. A. Russ. Chent. Rev. 1970, 39, 372. (b) Pfeffer, P. E.; Foglia, T. A.; Barr, P. A. Schmeltz, I.; Silbert, L. S. Tetrahedron Lett. 1972, 13, 4063. (c) Shaw, J. E.; Kunerth, D. C.; Sherry, J. J. Tetrahedron Lett. 1973, 14, 689. (d) Grundj, J.; James, B. G; Pattenden, G Tetrahedron Lett, 1972, 757. (e) Liotta, Gi L.; Harris, H. P.; Dermoth, M. M.; Gonzalez, T.; Smith, K. Tetrahedron Lett. 1974. 15. 2417. (f) Moore, G. G.; Foglia, T. A.; Mc Gahan, T. J. J. Org. Chem. 1979, 44.2425. (o) March, J. Reactions, Mechonisms, and Strtctire, 3 rd ed.; John Wiley and Sons: 1984; p 353. (h) Carey, F, A.; Sundberg, R. J. Avanced Organic Chemistry, 3rd ed.; Plenum Press: New York and London, 1990.

17. Galnelli, G.; Manescalchi, F. Synthesis 1975, 723.

18. Kabaza, K. G.; Chapados, B. R.; Gestwicki, J. E.; McGrath, J. L. J. Org. Chem. 2000, 65, 1210.

19. Gayo, L. M.; Suto, M. J. Tetrahedron Lett, 1997, 38,513.

20. Pelletier, J. M.; Kincaid, S. Tetrahedron Lett. 2000, 41, 797.

2l. Rademann, J.; Smerdka, J.; Jung, G.; Grosche, P.; Schmid, D. Angew: Chem. 2001, $/ 13,390$. 